\title{
ANATOMIA DA MADEIRA E CASCA DE Acacia tucumanensis Gris.
}

\author{
José Newton Cardoso Marchiori \\ Departamento de Ciências Florestais - Centro de Ciências Rurais. \\ UFSM - Santa Maria, RS.
}

\section{RESUMO}

São descritos os aspectos anatômicos da madeira e casca de Acacia tucumanensis Gris. São apresentados dados quantitativos de 33 caracteres do xilema secundário, bem como fotomicrografias e desenhos. A presença de fibras libriformes, placas de perfuração simples, parênquima paratraqueal e raios homogêneos, são os aspectos mais importantes na estrutura do lenho. A ocorrência de fibras septadas e de raios com até 3-4 células de largura, confirmam a posição da espécie no sub-gênero Aculeiferum Vassal (= série Vulgares Benth.). Na estrutura da casca destacam-se o líber duro em faixas tangenciais e o curso irregular dos raios na casca mediana. São também fornecidas fotomicrografias da casca.

\section{SUMMARY}

MARCHIORI, J.N.C., 1995. Anatomy of the Wood and Bark of Acacia tucumanensis Gris.

The wood and bark anatomy of Acacia tucumanensis Gris is described. Quantitative data from 33 different features of the secondary xylem are furnished, as well as photomicrographs and drawings of its structure. The presence of libriform fibres, simple perforation plates, paratracheal parenchyma and homogeneous rays, are important characteristics of the wood anatomy. The presence of septa in fibres and of rays with 3-4 cells wide, indicate the position of the species in the sub-genus Aculeiferum Vassal (= series Vulgares Benth.). Phloematic fibres in tangential bands, with 3-5 cells wide, and the irregular course of rays in the late bark, are the most conspicuous features of the bark structure. Photomicrographs of bark are also furnished. 


\section{INTRODUÇÃO}

O gênero Acacia (Tournef.) Miller compreende cerca de 1200 espécies (PEDLEY, 1986), distribuídas pelas regiões tropicais e subtropicais da América, África, Ásia e Austrália.

Acacia tucumanensis Gris. é uma árvore ou arbusto sub-trepador, originária da Bolivia, Paraguai, sul do Brasil e Províncias do centro e nordeste da Argentina (CIALDELLA, 1984). Para o Rio Grande do Sul, RAMBO (1966) registra sua presença nas regiões do Alto Uruguai, Depressão Central e Floresta Atlântica. Trata-se de uma espécie heliófila e seletiva higrófila (BURKART, 1979), que prefere a orla de matas, beira de estradas, capoeiras e formações abertas, sendo raramente encontrada no interior da mata densa. É conhecida popularmente como unha-de-gato, garapiá, vamos-junto (BURKART, 1979); garabato, garabato-blanco e garabatonegro (CIALDELLA, 1984).

Dependendo do autor, a espécie inclui-se na série Vulgares (BENTHAM, 1842), ou no sub-gênero Aculeiferum (VASSAL, 1972).

$\mathrm{O}$ presente trabalho visa a descrição dos caracteres gerais, macroscópicos e microscópicos da madeira, bem como o estudo da estrutura anatômica da casca. Os resultados são comparados com a literatura especializada, objetivando uma interpretação taxonômica e filogenética.

\section{REVISÃO DE LITERATURA}

A familia Leguminosae é vasta, cosmopolita, polimorfa e natural. A sua unidade como grupo taxonômico, embora contestada por diversos botânicos (HUTCHINSON, 1926; STRASSBURGER, 1949, TAKHTAJAN, 1969), é defendida por autores como BENTHAM (1876), ENGLER (1967) e BURKART (1952).

BURKART (1952) considera inadequada a elevação das sub-familias de Leguminosae para a categoria de família devido à existência de diversas espécies de transição, que impossibilitam uma delimitação satisfatória das entidades taxonômicas propostas.

Sob o ponto de vista da Anatomia da Madeira também não se verifica uma linha nítida de diferenciação entre estas sub-familias, motivo pelo qual, autores como RECORD \& HESS (1949), SENN (1943) e BARETTA KUIPERS (1981), preferem manter a unidade de Leguminosae.

A estrutura anatômica geralmente sugere que as madeiras de Mimosoideae são as menos especializadas e que as de Faboideae são as mais evoluídas. 
Em extenso estudo, incluindo 35 gêneros de Mimosoideae, 85 de Caesalpinioideae e 68 de Papilionoideqe, BARETTA-KUIPERS (1981) constatou que os raios fornecem as características mais importantes para a Taxonomia da Madeira, e que Caesalpinioideae tem a estrutura anatômica menos evoluída da família. Segundo a autora, esta sub-família constitui a base, a partir da qual a especialização anatômica progride em dua direções distintas : em direção a Mimosoideae, com a especialização dos raios, e em direção a Papilionoideae, com a estratificação de todos os elementos. É interessante observar que BURKART (1952) chegou à mesma conclusão, com base na morfologia externa.

REINDERS-GOUWENTAK (1955) analisou a estrutura da madeira de alguns gêneros de leguminosas da América do Sul, obtendo conclusões sobre o status taxonômico das subfamilias. De acordo com o autor, a distribuição do caráter "estrutura estratificada" torna conveniente a divisão das leguminosas em duas famílias, Mimosaceae e Papilionaceae, esta última sendo composta de duas sub-famílias. Para a caracterização anatômica da madeira dos diferentes táxones de Leguminosae, REINDERS-GOUWENTAK \& RIJSDIJK (1955) utilizaram caracteres da estratificação, bem como a estrutura e forma das células marginais dos raios.

BARETTA-KUIPERS (1981) observa que as madeiras de Mimosoideas podem ser facilmente distinguidas pela ausência de estratificação e por terem raios sempre homocelulares, compostos por células procumbentes de secção pequena (em secção tangencial) e baixas (secção radial). A autora refere que este último aspecto é dificilmente encontrado em gêneros de Caesalpinioideae e Papilionoideae, estando neste caso associado à estratificação dos raios.

$\mathrm{Na}$ identificação das tribos de Leguminosas, BARETTA-KUIPERS ( 1981) destaca como importantes o tipo de raios (homocelulares ou heterocelulares), a presença de raios uni ou multisseriados e a ocorrência de estratificação. Segundo a mesma autora, a distribuição do parênquima axial tem maior utilidade na distinção de gêneros e espécies.

Com relação ao gênero Acacia, destacam-se na história de sua Taxonomia os sistemas desenvolvidos por Bentham e Vassal.

BENTHAM (1842) reconheceu seis séries fundamentais, baseadas em caracteres clássicos da morfologia floral e do aparelho vegetativo Vulgares, Filicinae, Gummiferae, Botryocephalae, Phyllodineae e Pulchellae. Destas, apenas as três primeiras possuem representantes na flora americana.

VASSAL $(1963,72)$ propôs uma nova classificação natural, baseada em caracteres filéticos da morfologia da semente e plântulas. Suas observações levaram-no a restaurar o gênero monotípico aidherbia (F. albida (Del.) A. Chev.) e a dividir Acacia nos sub-gêneros Aculeiferum, 
Acacia e Heterophyllum. Segundo o autor, Aculeiferum baseia-se nas séries Vulgares e Filicinae de Bentham; o sub-gênero Acacia compreende as espécies da série Gummiferae Benth., com exceção de Acacia albida Del., e Heterophyllum reúne as séries Botryocephalae, Phyllodineae e Pulchelae de Bentham

Os estudos de anatomia da madeira são ainda relativamente escassos, face à importância econômica e extensão do gênero Acacia. Mesmo em obras clássicas, as referências são sumamente reduzidas. RECORD \& HESS (1949), por exemplo, não tratam do mesmo, apesar das centenas de espécies nativas no continente americano.

COZZO (1951), em importante estudo sobre as madeiras de Mimosoídeas e Cesalpinioídeas argentinas, observou que Acacia constitui um grupo estruturalmente homogêneo, no qual não se registram diferenças anatômicas relevantes. $\mathrm{O}$ autor relaciona uma série de detalhes estruturais de treze espécies e fornece uma chave dicotômica para a identificação das mesmas, baseada em caracteres anatômicos.

ROBBERTSE et al. (1980), em estudo de 37 espécies sul-africanas de Acacia, encontrou pouca variação na anatomia da madeira. A dimensão dos raios e, com menor importância, a presença de anéis de crescimento, número de poros por $\mathrm{mm}^{2}$ e distribuição do parênquima axial, foram os principais caracteres utilizados para a distinção de sub-gêneros. Os autores salientam que todas as 14 espécies examinadas, pertencentes ao sub-gênero Aculeiferum, tinham raios estreitos (25 seriados), ao passo que as 23 espécies do sub-gênero Acacia, apresentavam raios mais largos (414-seriados).

COZZO (1951) elaborou uma chave de identificação para as espécies argentinas de Mimosoídeas e Cesalpinioídeas, incluindo 10 espécies de Acacia, dentre as quais Acacia caven e $A$. bonariensis. O referido trabalho também fornece caracteristicas da madeira para os distintos gêneros representados na flora argentina.

A madeira de Acacia caven foi descrita sucintamente por WIEDENBRUG (1948). TORTORELLI (1956) fez uma descrição mais detalhada da mesma, incluindo informações sobre a distribuição geográfica e utilizações da madeira, além de descrições botânica e anatômica (macro e microscópica) do xilema. MARCHIORI (1992) estudou a madeira e casca da mesma, com base em amostras procedentes do Rio Grande do Sul.

MARCHIORI (1993) descreveu a anatomia da madeira de Acacia ibirocayensis, observando semelhanças estruturais com Acacia caven e o descrito por ROBBERTSE et al. (1980), para espécies sul-africanas do sub-gênero Acacia. 
Em estudo descritivo da madeira de Acacia recurva Benth., MARCHIORI (1982) encontrou fibras libriformes septadas, parênquima axial pouco abundante, fibras vivas e de paredes finas na periferia do parênquima paratraqueal, e raios predominantemente uni ou bisseriados. Tais caracteres, segundo o autor, são comuns entre espécies nativas da série Vulgares Benth. (= subgênero Aculeiferum Vassal).

Para Acacia plumosa Lowe, MARCHIORI (1991.A) destacou, ainda, a presença de parênquima axial em séries de 2-4 células, o confinamento de cristais à periferia dos anéis de crescimento e, sobretudo, a ocorrência de canais intercelulares axiais e de canais celulares nos raios. A presença destes canais foi também reportada por MARCHIORI (1991.B) para a madeira de Acacia nitidifolia Speg.

A literatura sobre a anatomia da casca é ainda mais fragmentária do que a do xilema, notadamente para as espécies sul-americanas.

TEIXEIRA et al. (1979) estudaram a estrutura de 4 espécies de Dalbergia e elaboraram, pela primeira vez no Brasil uma chave de identificação baseada em caracteristicas do floema secundário.

ROTH (1977) estudou a casca de 22 espécies arbóreas da floresta tropical pluvial da Guiana Venezuelana, pertencentes a 7 diferentes gêneros de Mimosoideas . O gênero Acacia, entretanto, não foi incluído. Segundo a autora, a sub-familia constitui um grupo relativamente homogêneo quanto à estrutura do floema, apresentando importantes características anatômicas em comum. O liber duro ocorre na forma de fibras típicas, agrupadas em placas tangenciais estreitas, alternantes com faixas de tecido parenquimático. Não ocorrem células pétreas na casca interna e os raios, embora multisseriados, não alcançam largura considerável. Não ocorrem canais secretores, mas apenas células secretoras em curtas fileiras tangenciais. O crescimento de dilatação é moderado, formando-se células pétreas ao final da casca mediana. O súber é estratificado e o feloderma desenvolve células pétreas, tendendo à estratificação. ROTH (1977) compara estas caracteristicas com o verificado nas Sapotaceae, sobretudo pelo agrupamento do liber duro e formação de células secretoras.

\section{MATERIAL E MÉTODOS}

O material estudado é procedente do Estado do Rio Grande do Sul e consiste de amostras do tronco de 5 árvores, contendo casca e madeira. As amostras, com a forma de disco e cerca de $3 \mathrm{~cm}$ de espessura, foram fixadas em FAA imediatamente após a coleta, sendo desta forma 
conservadas até o início dos trabalhos de microtécnica. Para cada indivíduo foram também preparadas exsicatas botânicas, incorporadas ao Herbário do Departamento de Ciências Florestais com os números $06,307,339,340$ e 341. Para o preparo das lâminas usaram-se procedimentos distintos para madeira e casca.

Para a obtenção de lâminas de cortes anatômicos do xilema foram preparados 3 bloquinhos, orientados segundo os planos transversal, longitudinal radial e longitutinal tangencial, respectivamente. Os bloquinhos foram amolecidos por fervura em água. Usou-se micrótomo de deslizamento e espessura nominal de corte de $18 \mu \mathrm{m}$. Os cortes foram coloridos com vermelho de acridina, crisoidina e azul de astra (DUJARDIN, 1964), desidratados em série alcoólica, diafanizados com xilol e montados em lâminas permanentes com "Entellan"

Para a obtenção de lâminas de cortes anatômicos da casca foram também preparados bloquinhos segundo os 3 planos anatômicos, abrangendo toda a espessura da casca, o câmbio e uma estreita região adjacente de xilema. Os bloquinhos foram fervidos em água para o amolecimento dos tecidos, incluídos em celoidina e cortados em diferentes espessuras, de acordo com o material e plano anatômico.

Cada corte transversal ou longitudinal radial, obtido desta forma, inclui o conjunto dos tecidos extra-xilemáticos, mostrando as transformações verificadas na casca ao longo de toda a sua extensão. O plano longitudinal tangencial, por sua vez, mostra em cada corte o aspecto da estrutura anatômica de apenas uma determinada região da casca, sendo portanto necessária a obtenção de cortes em diferentes profundidades. Os cortes sofreram coloração e montagem de acordo com o exposto anteriormente.

No preparo de lâminas de macerado, tanto de xilema como de floema, foram obtidos finos palitos, retirados da parte mais externa do alburno. Os palitos foram fervidos em água para a expulsão completa do ar, sendo posteriormente submetidos à maceração em solução de Jeffrey (FREUND, 1970). A pasta de celulose foi neutralizada, colorida com safranina, desidratada e conservada em frasco hermético com xilol, até a montagem de lâminas permanentes

Para a descrição da estrutura antômica da madeira seguiu-se a COPANT (1973), com as modificações introduzidas por TEIXEIRA (1977), MARCHIORI (1980) e MUÑIZ (1986) Os dados numéricos são apresentados na Tabela 1.

Para a descrição da casca seguiu-se ROTH (1977), tendo sido determinados apenas o comprimento e diâmetro médio de elementos crivados e fibras floemáticas, com base em 20 medições de cada caráter e amostra. 
A fotomacrografia (Figura 1) foi obtida em aparelho Aristofot, marca Leitz. Para as fotomicrografias das Figuras 2, 4, 6 e 7, utilizou-se um aparelho Carl Zeiss. Os desenhos foram feitos com o uso de câmara clara. A cor da madeira foi definida com o uso da Tabela de Cores para Solos (MUNSELL, 1971).

\section{DESCRIÇÃO DA MADEIRA}

\section{Caracteres gerais :}

Cerne e alburno distintos. Alburno estreito, de cor amarela (HUE 2.5 Y 8/6). Cerne castanho-escuro (HUE 10 YR 6/4), com veios marrons (HUE 10 YR 4/3). Madeira sem brilho, de grã direita a inclinada, não aromática, moderadamente dura e de textura média. Figura homogênea.

\section{Caracteres macroscópicos :}

Parênquima axial : Visivel a olho nu, pouco abundante, em arranjo paratraqueal vasicêntrico e faixas marginais (Figura 1)

Raios : Invisíveis a olho nu em plano transversal, finos, numerosos. Em plano longitudinal tangencial, visiveis com dificuldade sob lente, baixos, não estratificados.

Poros: Visiveis a olho nu em plano transversal, de diâmetro médio, muito numerosos. Poros em distribuição semi-difusa, solitários, e em múltiplos radiais de 2 ou 3. Os poros de lenho inicial apresentam diâmetro nitidamente maior do que os de lenho tardio (Figura 1). Linhas vasculares retilíneas, freqüentemente obstruidas por conteúdo marrom-avermelhado-escuro, sobretudo em região de cerne. No alburno observa-se intenso brilho sedoso, na forma de curtos segmentos ao longo das linhas vasculares. Espelhado dos raios, pouco contrastado.

Camadas de crescimento : Distintas, marcadas pela distribuição dos poros em anéis semi-porosos e parênquima marginal (Figura 1)

Outros caracteres : Canais secretores axiais, máculas medulares, liber incluso, listrado de estratificação e canais secretores radiais, ausentes.

\section{Caracteres microscópicos :}

Vasos: Distribuídos em anéis semi-porosos; muito numerosos (14-23-33 poros $/ \mathrm{mm}^{2}$ ), e ocupando $41,6$ \% da secção transversal da madeira. Poros de diâmetro pequeno a grande (77 - $151-235 \mu \mathrm{m})$ e forma oval. No início do anel, os poros tem diâmetro nitidamente maior do que no lenho tardio, havendo predominância de solitários e múltiplos radiais de 2 a 3 (Figura 2. A,B). Em direção ao 
término do anel de crescimento encontram-se numerosos agrupamentos radiais e em cacho, que reúnem poros de diâmetro muito pequeno e forma poligonal (Figura 2. B,C).

Elementos vasculares muito curtos (120 - $241-313 \mu \mathrm{m})$, com placas de perfuração simples, tendentes a transversal ao vaso (Figura 2.D; 3.A-F). Apêndices ausentes, ou então, curtos (12,5 $37-75 \mu \mathrm{m}$ ), dispostos geralmente em uma única extremidade. Espessamentos espiralados, ausentes. Inclusões orgânicas com o aspecto de goma, abundantes em vasos do cerne.

Pontuações intervasculares ornamentadas, de diâmetro médio (7-8,1-9 $\mu \mathrm{m})$, e forma circular até poligonal; com aberturas horizontais, lenticulares, inclusas ou curto-coalescentes a poucas pontuações (Figura 4. C,D).

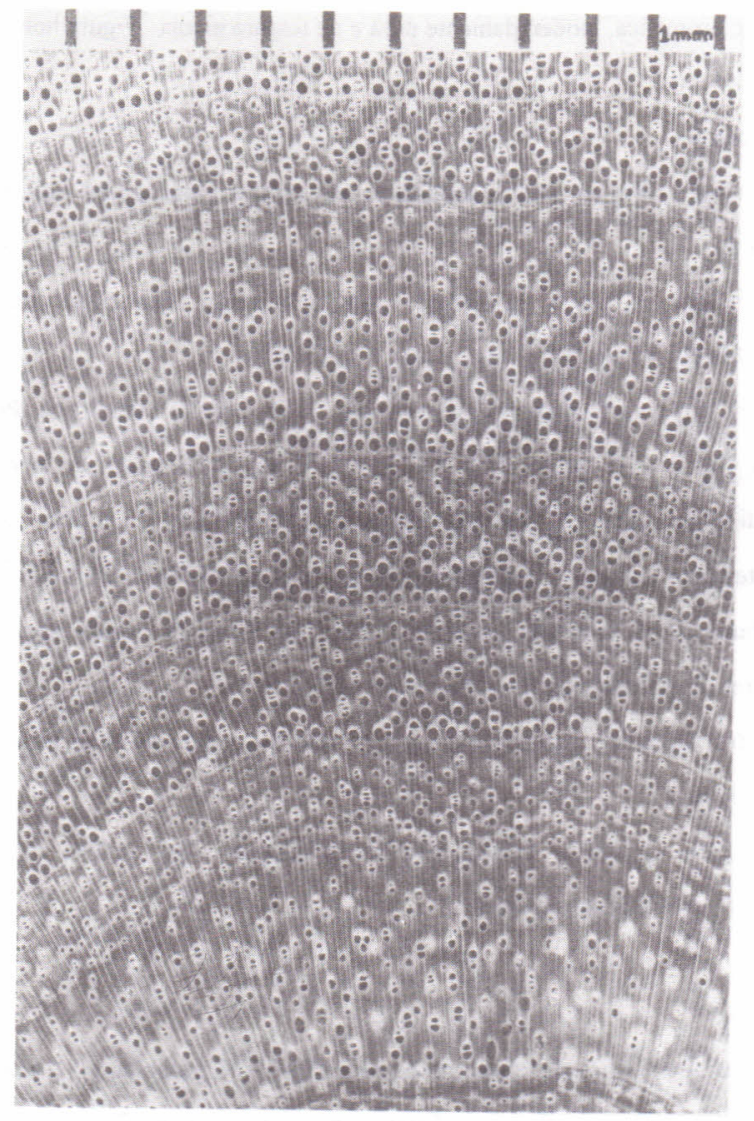

$\$$

Figura 1. Fotomicrografia do xilema secundário $($ escala $=1 \mathrm{~mm})$. 
Pontuações raio-vasculares pequenas a médias $(5,5-7-10 \mu \mathrm{m})$ e arredondadas. Pontuações parênquimo-vasculares também pequenas a médias $(5,5-6,8-10 \mu \mathrm{m})$, semelhantes às anteriores.

Parênquima axial: Ocupando apenas $7,2 \%$ do volume da madeira; em arranjo nitidamente paratraqueal, desde vasicêntrico até confluente, e apotraqueal marginal (Figura 2.A-C). A aparente abundância observada em plano transversal deve-se à concentração de fibras de parede muito fina, formando largo envoltório adjacente ao parênquima paratraqueal.
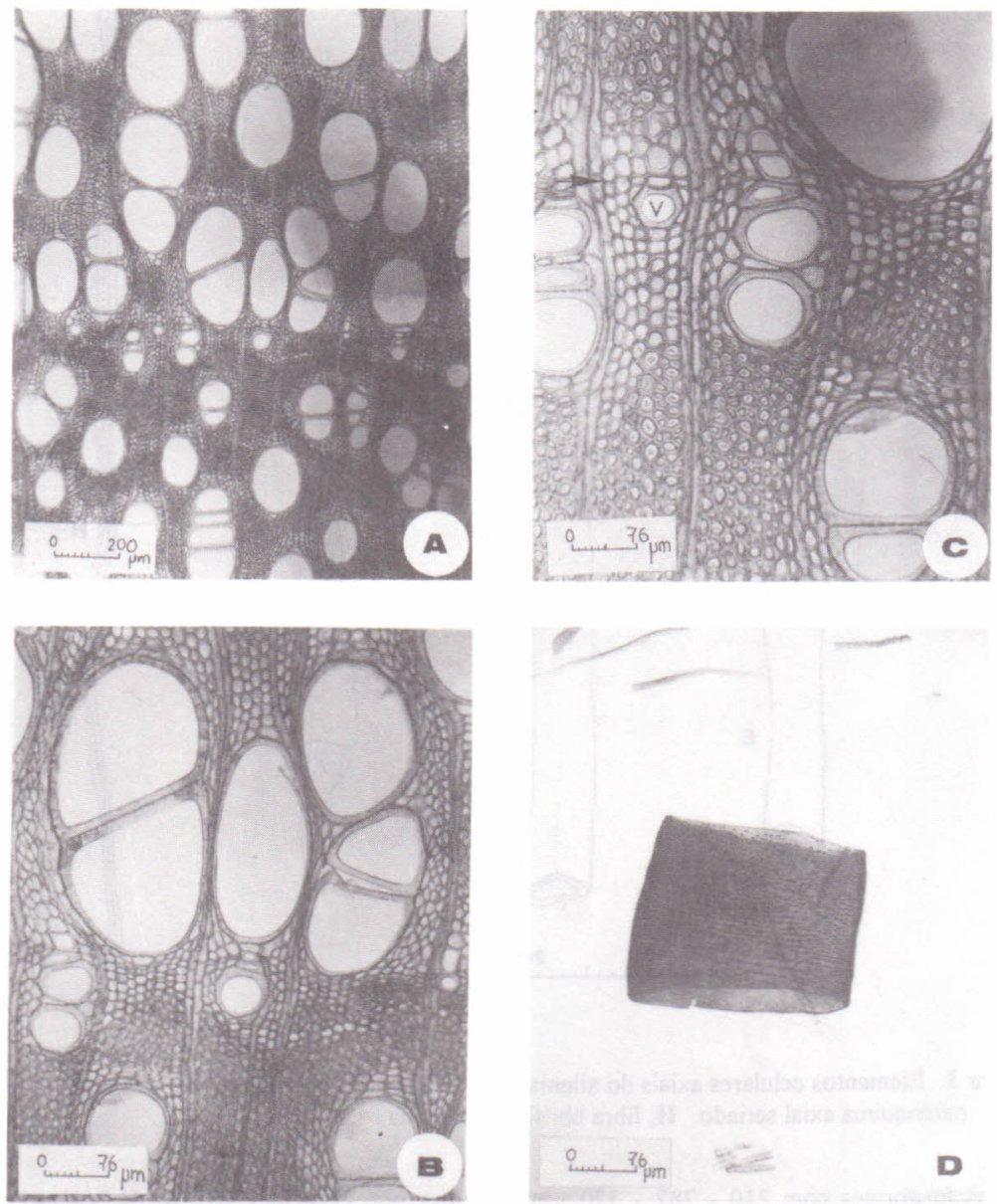

Figura 2. Aspectos anatômicos do xilema. A. Secção transversal, mostrando limite de anel de crescimento no centro do campo. B. Seç̧ão transversal, destacando a diferença no diâmetro dos poros entre os lenhos tardio e inicial. C. Detalhe do limite de um anel de crescimento (setas), destacando o parênquima marginal (PA) e o contorno poligonal dos vasos de lenho tardio $(\mathrm{V})$. D. Elemento vascular de lenho inicial. 


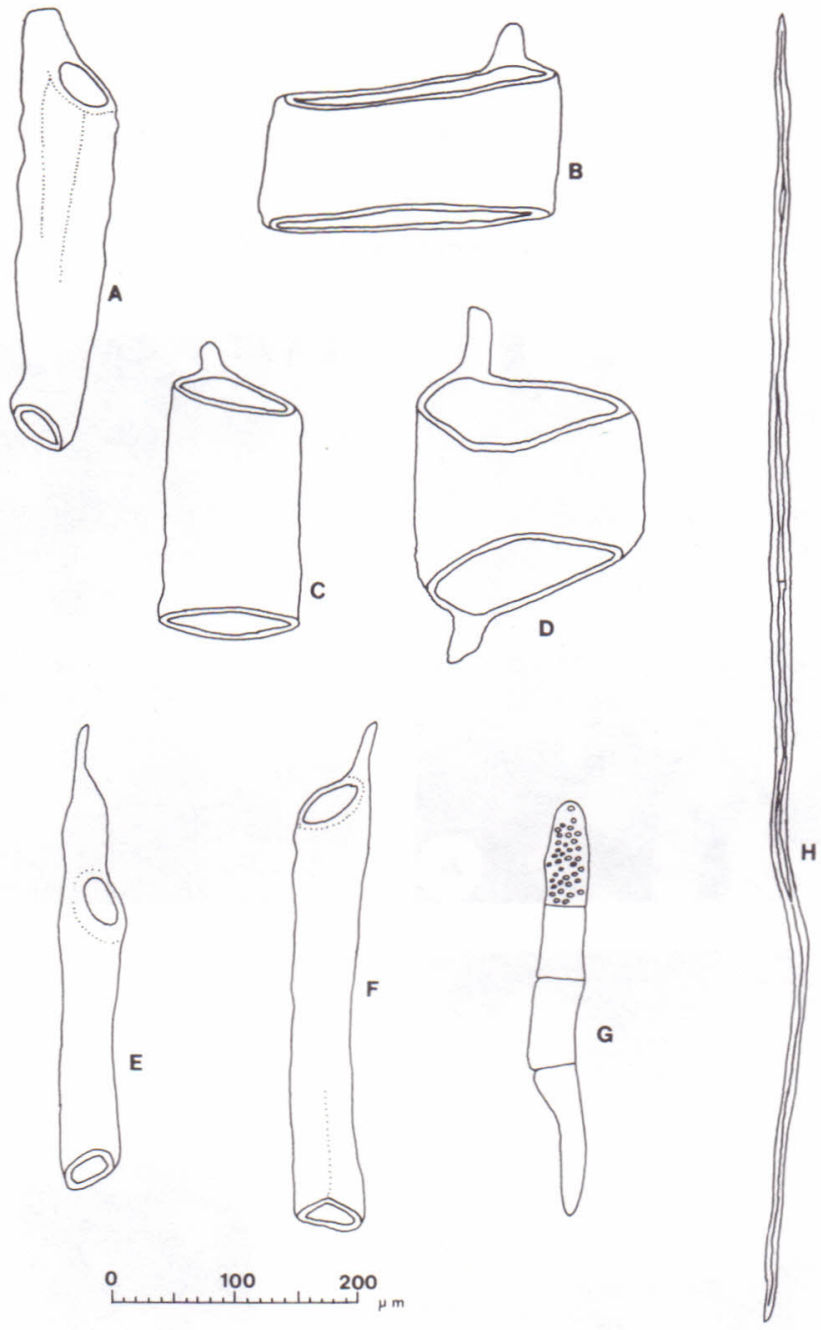

t)

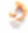

Figura 3. Elementos celulares axiais do xilema. A-F, elementos vasculares. G, células de parênquima axial seriado. $\mathbf{H}$, fibra libriforme septada.

Células fusiformes com $210-287-370 \mu \mathrm{m}$ de altura por $12-17-23 \mu \mathrm{m}$ de largura, sendo compostas por 2 - 4 - 8 células (Figura 3.G).

Monocristais romboédricos de oxalato de cálcio, com cerca de $25 \mu \mathrm{m}$ de de comprimento, presentes em numerosas câmaras por série, sobretudo na periferia dos anéis de crescimento, onde formam um envoltório quase completo. 
Raios : Tecido radial homogêneo, composto inteiramente de células horizontais (Figura 4.A,B), e compondo $8,7 \%$ do volume da madeira. Raios muito numerosos ( 8 - 10,7 - 15 raios $/ \mathrm{mm}$ ), e de relacionamento normal. Raios agregados e axialmente fusionados, ausentes (Figura 4.C,D).

Raios unisseriados pouco freqüentes ( 9 - 14 - $17 \%$ do total); extremamente baixos (22 - 73 - 223 $\mu \mathrm{m})$, de extremamente finos a muito finos $(8-12-19 \mu \mathrm{m})$ e com 2 - 6 - 19 células de altura (Figura 5.A-G).

Raios multisseriados com 3 células de largura em sua maioria (43,5\%), menos comumente
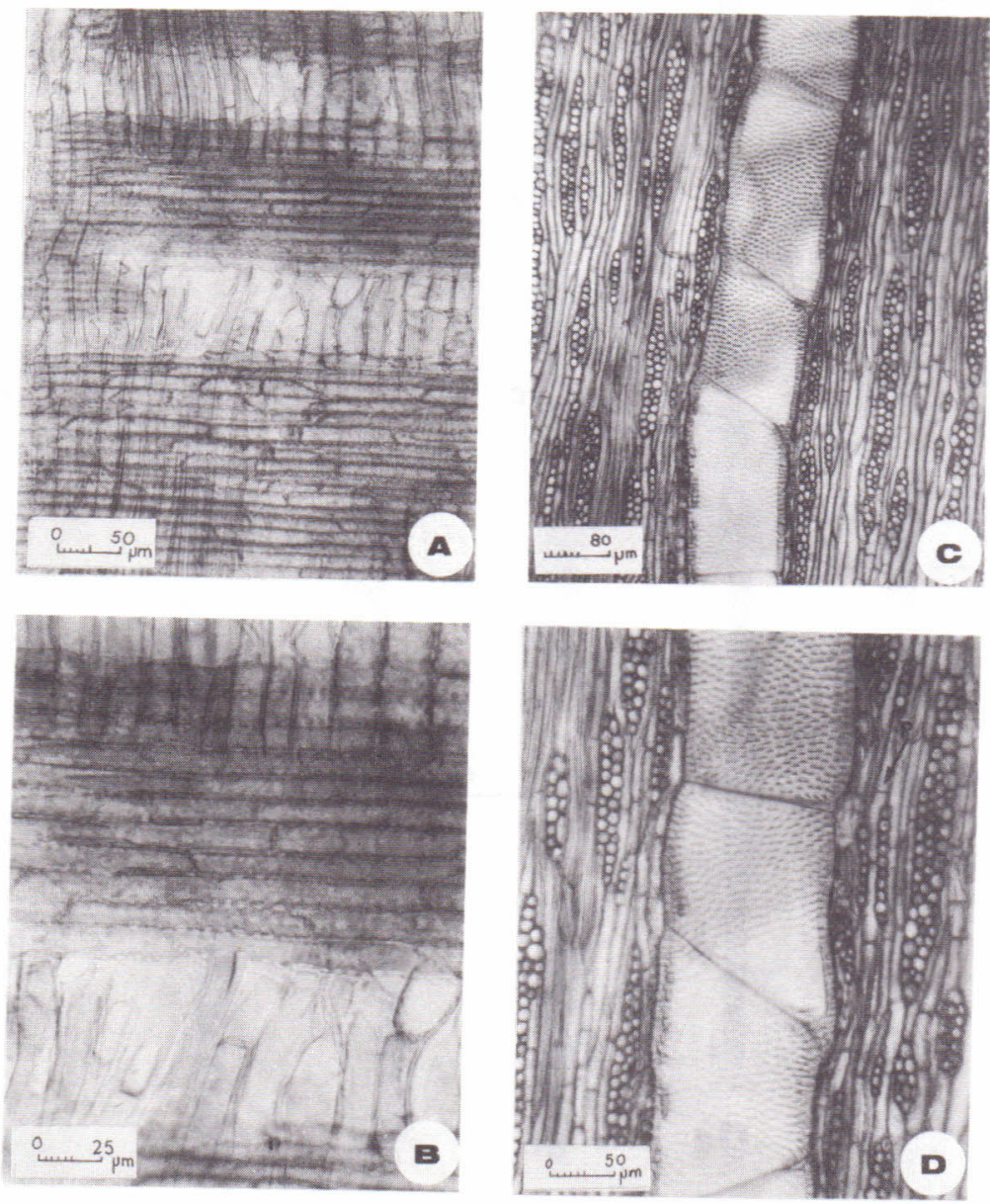

Figura 4. Aspectos do xilema secundário. A. Estrutura radial homogênea. B. Raio composto inteiramente de células horizontais. C. Aspecto da secção tangencial. D. Pontuado intervascular, parênquima axial (PA) e raios, em secção tangencial. 
bisseriados $(23,7 \%)$ e tetrasseriados (18,8 \%); extremamente baixos (97 - 257 - $570 \mu \mathrm{m})$, muito finos ( $15-28-36 \mu \mathrm{m}$ ), e com $7-21-45$ células de altura. Raios com mais de 4 células de largura, ausentes (Figura 5.H-P).

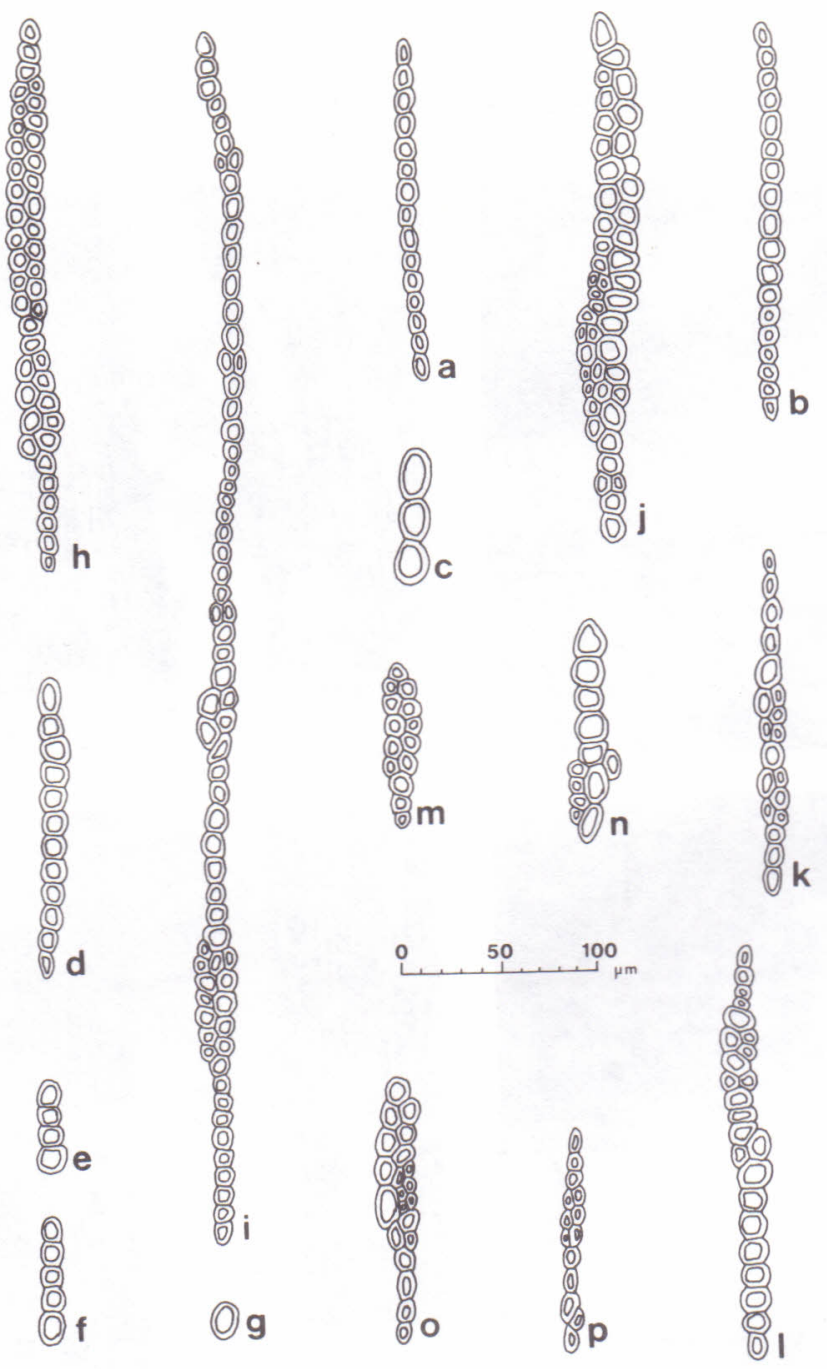

Figura 5. Formas de raios xilemáticos, em secção longitudinal tangencial. A-G, raios unisseriados. H,I,K, L,P, raios com mais de uma região multisseriada. $\mathbf{J}, \mathbf{M}, \mathbf{N}, \mathbf{O}$, raios multisseriados. 
Células cristaliferas, envolventes, eretas, quadradas, latericuliformes, oleiferas e esclerosadas, ausentes no tecido radial (Figura 4.A-D)

Fibras: Ocupando área comparável à dos poros em secção transversal (42,5\%). Fibras libriformes, septadas e providas de diminutas pontuações simples, mais abundantes na face radial da parede (Figura 3.H). Fibras muito curtas até curtas $(930-1.120-1380 \mu \mathrm{m})$, estreitas $(10-17-24 \mu \mathrm{m}) \mathrm{e}$ com paredes de espessura muito variável $(1,9-5,2-7,5 \mu \mathrm{m})$. As fibras de parede fina concentramse na periferia do parênquima paratraqueal, formando faixas irregulares tangenciais ou obliquas, e de largura variável. Fibras gelatinosas, freqüentes

Outros caracteres : Canais intercelulares, tubos laticiferos e taniniferos, e liber incluso, ausentes. Anéis de crescimento distintos, evidenciados pelo tipo de porosidade, bem como pelo parênquima marginal e bainha cristalifera.

\section{DESCRIÇÃO DA CASCA}

\section{Casca interna}

De 500 A $1000 \mu$ m de espessura e com 4 a 7 faixas de liber tenro.

Liber duro em faixas tangenciais estreitas (cerca de $50 \mu \mathrm{m}$ ), com 3 a 5 fibras floemáticas de espessura, ou em feixes isolados. Faixas bastante regulares, mas ocasionalmente interrompidas no liber tenro (Figura 6.C).

Fibras floemáticas não septadas, de 700-1150-1650 $\mu \mathrm{m}$ de comprimento por 10-13-18 $\mu \mathrm{m}$ de diâmetro tangencial Figura 6.C).

Elementos crivados longos, de 245-303-368 $\mu \mathrm{m}$ de comprimento por 15-25-33 $\mu \mathrm{m}$ de diâmetro tangencial; dispostos em grupos tangenciais unisseriados ou bisseriados, pequenos, com 4 a 10 células e em posição central no liber tenro. Placa crivada múltipla em posição geralmente vertical, mas em ângulos de até $45^{\circ}$; apresentando de 15 a 25 áreas crivadas em arranjo reticulado, raramente escalariforme. Áreas crivadas com numerosos poros diminutos (Figura 7.B).

Parênquima axial abundante. Na periferia do liber duro estas células apresentam-se subdivididas em câmaras, cada uma contendo um monocristal romboédrico de oxalato de cálcio. Células acompanhantes aparentemente desprovidas de cristais. Células de parênquima axial, ricas em substâncias de forma granular ou fusiforme, e natureza não determinada. 
Raios homogêneos, semelhantes aos do xilema. Raios largos com região multisseriada relativamente curta, longas colas, e freqüentemente mais de uma região multisseriada por raio (Figura 6.D). Células de parênquima radial desprovidas de cristais.
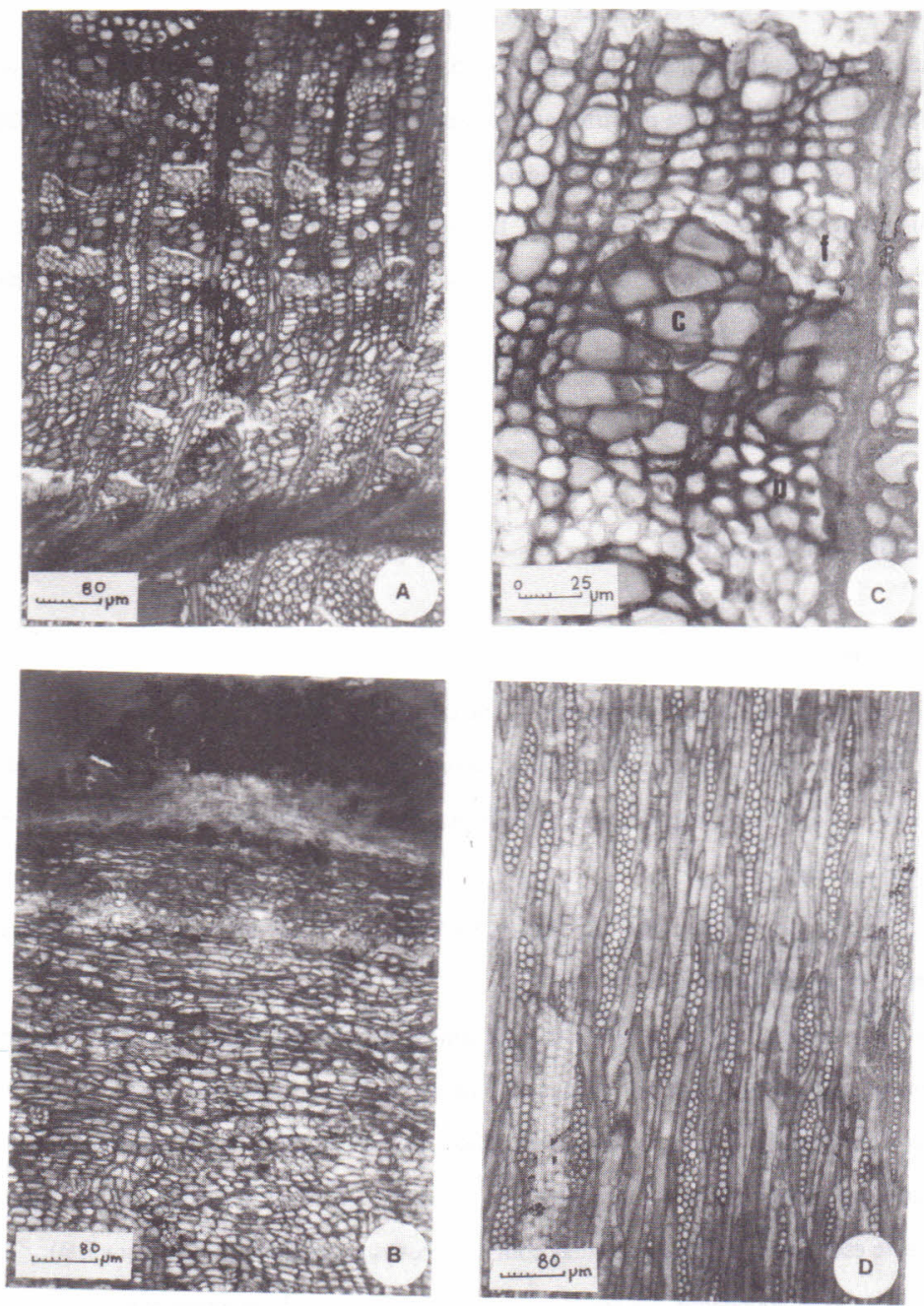

Figura 6. Aspectos da casca. A. Secção transversal da região externa do xilema secundário, região cambial e casca interna. B. Secção transversal das cascas mediana e externa. C. Detalhe da casca interna (secção transversal), mostrando feixes de elementos crivados (c), células acompanhantes. agrupamentos tangenciais de fibras (f) e parênquima floemático axial (p). D. Secção longitudinal tangencial da casca interna. 


\section{Casca mediana}

De espessura bastante variável $(800-1500 \mu \mathrm{m})$. Na região mais interna da casca mediana verificase a perda de protoplasma em elementos crivados e células acompanhantes. Em estágio posterior, estes elementos celulares são esmagados pelo crescimento de células parenquimáticas, até formarem uma massa irregular de cor escura.

O curso dos raios é irregular na casca mediana, mostrando muitas vezes crescimento por dilatação na parte mais externa, devido a intensas divisões anticlinais que subdividem os feixes de fibras floemáticas.

As células de parênquima axial também se dividem anticlinalmente, sobretudo mediante planos transversais. Em secção tangencial vê-se que o parênquima radial é proeminente na região mais externa, compondo-se de células tangencialmente alargadas $\mathrm{O}$ parênquima axial é comparativamente escasso e constituido por células curto-retangulares, à semelhança dos raios (Figura 6.B).

Na região mais externa da casca mediana observa-se a transformação de grande parte das células parenquimáticas em cristaliferas. Ao término da casca mediana forma-se uma bainha esclerenquimática continua, com cerca de 1 a 4 células de espessura, contendo de células pétreas e macro-esclerócitos, freqüentemente cristaliferos. O feloderme é bastante estreito, com 1 ou 2 células de espessura.
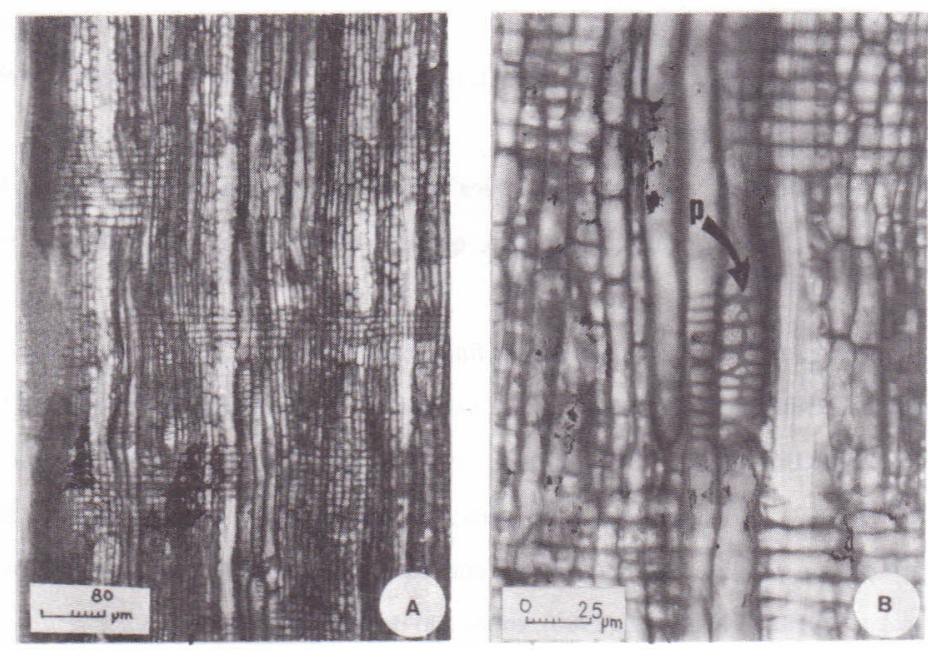

Figura 7. Fotomicrografias da casca, em secção longitudinal radial. A. Aspecto geral. B. Detalhe de placas crivadas compostas (p), em arranjos escalariforme e reticulado. 


\section{Casca externa}

Bastante estreita nos indivíduos estudados, contendo felema de células muito estreitas, com cerca de $5 \mu \mathrm{m}$ de diâmetro radial e fortemente suberizadas

\section{ANÁLISE DA ESTRUTURA ANATÔMICA}

Os principais caracteres anatômicos da madeira de Acacia tucumanensis correspondem integralmente ao descrito para as espécies do gênero e indicam um nível relativamente elevado de especialização. Detalhes como placas de perfuração simples em posição transversal ao vaso, pontuações intervasculares alternas e de diâmetro médio, parênquima nitidamente paratraqueal, tecido radial homogêneo e fibras libriformes, permitem esta afirmativa e são de ocorrência comum na familia Leguminosae, de acordo com METCALFE \& CHALK (1972), RECORD \& HESS (1949), COZZO (1951), BARETTA-KUIPERS (1981) e TORTORELLI (1956)

A ausência de estratificação no material estudado, associada a células radiais exclusivamente procumbentes e de secção pequena, são caracteres sugestivos da sub-família Mimosoideae, de acordo com BARETTA-KUIPERS (1981). A anatomia da madeira de Acacia tucumanensis também corresponde ao descrito para as Mimosoideas quanto à concentração de fibras mais curtas e de lúmem relativamente grande na periferia do parênquima paratraqueal. Este caráter é considerado importante por METCALFE \& CHALK (1972), para a separação de espécies entre esta sub-familia e Cesalpinioideae

A análise da estrutura anatômica de Acacia nucumanensis também fornece interessantes observações de cunho taxonômico, quando comparada com descrições de espécies afins

A presença de raios multisseriados finos, com geralmente 3 e no máximo 4 células de largura, permite distinguir prontamente Acacia tucumanensis de Acacia caven (MARCHIORI, 1992; WIEDENBRUG, 1948, TORTORELLI, 1956; COZZO, 1951) e Acacia ibirocayensis (MARCHIORI, 1993), pertencentes ao sub-gênero Acacia de Vassal (= série Gummiferae Benth.). A caracterização do sub-gênero Acacia Vassal, com base neste aspecto anatômico, já havia sido considerada por ROBBERTSE et al. (1980), em estudo de espécies sul-africanas.

A presença exclusiva de pequenos cristais romboédricos de oxalato de cálcio em séries de câmaras parenquimáticas axiais, também distingue a espécie em estudo do verificado com as duas espécies citadas. Nestas, observa-se ainda - e com maior conspicuidade - a ocorrência de 
idioblastos com macro-cristais de até $80 \mu \mathrm{m}$ de diâmetro, facilitando sobremaneira a separação das mesmas.

A espécie em estudo assemelha-se à diversas espécies investigadas do sub-gêrero Aculeiferum Vassal (COZZO, 1951; MARCHIORI, 1982, 1991.A, 1991.B), pela presença de fibras septadas. Este caráter, de acordo com FAHN \& LESHEM (1963), ocorre geralmente em arbustos e sub-arbustos, hábito mais freqüente nas espécies do referido sub-gênero. É interessante notar-se que as espécies do sub-gênero Acacia também se distinguem neste particular, por terem fibras não septadas (MARCHIORI, 1992, 1993).

TABELA 1. Dados quantitativos do xilema.

\begin{tabular}{|c|c|c|c|c|c|}
\hline Característica anatômica & $\begin{array}{l}\mathrm{N}^{\circ} \\
\mathrm{Med}\end{array}$ & V. Mínimo & Média & $\begin{array}{c}\mathrm{V} \\
\text { Máximo } \\
\end{array}$ & $\begin{array}{r}\text { D. } \\
\text { Padrão } \\
\end{array}$ \\
\hline 01. Fração de poros (5) & 1200 & 36 & 41,6 & 48,0 & 4,22 \\
\hline 02. Freqüência de poros (poros $/ \mathrm{mm}^{2}$ ) & 60 & 14 & 22,7 & 33 & 4,82 \\
\hline 03. $\varnothing$ poros solitários $(\mu \mathrm{m})$ & 60 & 77,0 & 151,0 & 235,0 & 38,90 \\
\hline 04. E. parede de poros $(\mu \mathrm{m})$ & 60 & 4,3 & 5,9 & 8,1 & 1,11 \\
\hline 05. C. elementos vasculares $(\mu \mathrm{m})$ & 60 & 120,0 & 241,4 & 312,5 & 43,32 \\
\hline 06. C. de apêndices $(\mu \mathrm{m})$ & 40 & 12,5 & 36,8 & 75,0 & 21,38 \\
\hline 07. $\oslash$ pont. intervasculares $(\mu \mathrm{m})$ & 40 & 7,0 & 8,1 & 9,0 & 0,59 \\
\hline $08 . \emptyset$ pont. raio-vasculares $(\mu \mathrm{m})$ & 40 & 5,5 & 7,1 & 10,0 & 1,15 \\
\hline 09.Øpont.parênquimo-vasculares $(\mu \mathrm{m})$ & 40 & 5,5 & 6,8 & 10,0 & 1,18 \\
\hline 10. Fração parênquima axial (\%) & 1200 & 6 & 7,2 & 9 & 1,16 \\
\hline 11. H. séries parênquima axial $(\mu \mathrm{m})$ & 60 & 237,5 & 289,8 & 362,5 & 35,21 \\
\hline 12. H. séries parênquima axial (céls.) & 60 & 2 & 3,8 & 8 & 1,95 \\
\hline 13. L. séries parênquima axial $(\mu \mathrm{m})$ & 60 & 12,5 & 19,2 & 26,3 & 3,46 \\
\hline 14. H. células fusiformes $(\mu \mathrm{m})$ & 60 & 210,0 & 286,7 & 370,0 & 31,48 \\
\hline 15. L. células fusiformes $(\mu \mathrm{m})$ & 60 & 12,5 & 16,8 & 22,5 & 3,48 \\
\hline 16. Fração tecido radial (\%) & 1200 & 6 & 8,7 & 13 & 3,01 \\
\hline 17. Frequência de raios (raios $/ \mathrm{mm}$ ) & 60 & 8 & 10,7 & 15 & 1,78 \\
\hline 18. Fração raios unisseriados $(\%)$ & 1200 & 9 & 14,0 & 17 & 3,03 \\
\hline 19. H. raios unisseriados $(\mu \mathrm{m})$ & 60 & 22 & 73,3 & 222,5 & 46,81 \\
\hline 20. H. raios unisseriados (células) & 60 & 2 & 5,9 & 19 & 3,79 \\
\hline 21. L. raios unisseriados $(\mu \mathrm{m})$ & 60 & 8 & 11,8 & 18,8 & 2,69 \\
\hline 22. H. raios multisseriados $(\mu \mathrm{m})$ & 60 & 97,5 & 257,0 & 570,0 & 120,01 \\
\hline 23. H. raios multisseriados (células) & 60 & 7 & 21,2 & 45 & 10,00 \\
\hline 24. L. raios multisseriados $(\mu \mathrm{m})$ & 60 & 15 & 27,8 & 36,3 & 5,95 \\
\hline 25. L. raios multisseriados (células) & 60 & 2 & 3 & 4 & 0,66 \\
\hline 26. Fração raios 2 -seriados $(\%)$ & 1200 & 21 & 23,7 & 29 & 3,14 \\
\hline 27. Fração raios 3 -seriados ( $\%$ ) & 1200 & 39 & 43,5 & 48 & 4,13 \\
\hline 28. Fração raios 4-seriados (\%) & 1200 & 13 & 18,8 & 25 & 4,62 \\
\hline 29. Fração de fibras (\%) & 1200 & 34 & 42,5 & 49 & 6,28 \\
\hline 30. C. de fibras $(\mu \mathrm{m})$ & 60 & 930,0 & 1120,0 & 1380,0 & 119,07 \\
\hline 31. $\varnothing$ de fibras $(\mu \mathrm{m})$ & 60 & 10 & 17,3 & 23,8 & 2,88 \\
\hline 32. Ø lúmem de fibras $(\mu \mathrm{m})$ & 60 & 2,5 & 6,9 & 12,5 & 2,96 \\
\hline 33. Espessura parede de fibras $(\mu \mathrm{m})$ & 60 & 1,9 & 5,2 & 7,5 & 1,29 \\
\hline
\end{tabular}


Com relação à largura dos raios, a espécie em estudo assemelha-se ao observado em Acacia recurva Benth. (MARCHIORI, 1982), Acacia nitidifolia (MARCHIORI, 1991.B) e Acacia plumosa (MARCHIORI, 1991.A), pertencentes ao sub-gênero Aculeiferum Vassal (= série Vulgares Benth.)

A estrutura anatômica de Acacia tucumanensis, deste modo, reforça a identidade destes táxones infra-genéricos, confirmando a hipótese original de MARCHIORI (1980).

Com relação à estrutura da casca, os caracteres mais importantes de Acacia tucumanensis correspondem ao descrito por ROTH (1977). Para a identificação da espécie em estudo, cabe ressaltar a presença de liber duro em faixas tangencias de 3 a 5 fibras floemáticas de espessura e o curso irregular dos raios na casca mediana.

\section{LITERATURA CITADA}

BARETTA-KUIPERS, T. Wood anatomy of Leguminosae: its relevance to Taxonomy. In POLHILL, R.M. \& RAVEN, P.H. Advances in Legume Systematics. 1981. p. 677-715.

BENTHAM, . Notes on Mimoseae, with a sunopsis of species. The London Journ. of Botany, 1: 318-392; 494-518. 1842.

BENTHAM, G. Leguminosae III. Mimoseae. In : MARTIUS, C.F. P. von. Flora Brasiliensis. 1876. 15(2): 259-527.

BURKART, A Las Leguminosas Argentinas Silvestres y Cultivadas. Buenos Aires, ACME Agency, 1952. $569 \mathrm{p}$.

BURKART, A. Leguminosas Mimosoideas. In : REITZ, R. Flora Ilustrada Catarinense. Itajaí, 1979. $299 \mathrm{p}$.

CIALDELLA, A.M. El género Acacia en la Argentina. Darwiniana, 25(1-4): 59-111, 1984.

COMISION PANAMERICANA DE NORMAS TECNICAS. n 30, p. 1-19, nov. 1973.

COZZO, D. Anatomia del leño secundario de las leguminosas mimosoideas y caesalpinoideas argentinas silvestres y cultivadas. Rev. Inst. Nac. Invest. Ci. Nat. C. Bot., 2(2): 63-290, 1951

DUJARDIN, E.P. Eine neue holz-zellulosenfaerbung. Mikrokosmos, 53: 94, 1964.

ENGLER, A. Syllabus der Pflanzenfamilien. Berlin, Gebruender Borntraeger, 1967. V. 2, 367 p.

FAHN, A. \& LESHEM, B. Wood fibres with living protoplasts. New Phytol., 62(1): 91-98, 1963.

FREUND, H. Handbuch der Mikroskopie in der Technik. Frankfurt, Umsham Verlag, 1970 $375 \mathrm{p}$.

HUTCHINSON, J. The families of flowering plants arranged according to a new system based upon probable phylogeny. I. Dicotyledons. London, The Mc Millan Co., 1926. 328 p. 
MARCHIORI, J.N.C. Estudo anatômico do xilema secundário e da casca de algumas espécies dos gêneros Acacia e Mimosa, nativas no Estado do Rio Grande do Sul. Curitiba, Universidade Federal do Paraná, 1980. Dissertação. Mestrado. Setor de Ciências Agrárias. Curso de Pós-Graduação em Engenharia Florestal.

MARCHIORI, J.N.C. Estudo anatômico do xilema secundário e da casca de Acacia recurva Benth. (Leguminosae Mimosoideae). Ciência e Natura, 5: 95-105, 1982.

MARCHIORI, J.N.C. Anatomia da madeira de Acacia phumosa Lowe (Leguminosae Mimosoideae). Ciência e Natura, 13: 67-77, 1991. A.

MARCHIORI, J.N.C. Anatomia da madeira de Acacia nitidifolia Speg. (Leguminosae Mimosoideae). Ciência Florestal, 1(1): 46-63, 1991. B.

MARCHIORI, J.N.C. Anatomia da madeira e casca do espinilho, Acacia caven (Mol.) Mol. Ciência Florestal, 2(1): 27-47, 1992.

MARCHIORI, J.N.C. Estudo anatômico do xilema secundário de Acacia ibirocayensis Marchiori (Leguminosae Mimosoideae). Ciência e Natura, 1993.

METCALFE, C.R. \& CHALK, L. Anatomy of the Dicotyledons. Oxford, Clarendon Press, 1972. $1500 \mathrm{p}$.

MUÑIZ, G.I.B. de. Descrição da estrutura e ultra-estrutura da madeira de cinco espécies de Prosopis da Argentina e análise da Metodologia. Curitiba, Universidade Federal do Paraná, 1986. 192 p. Dissertação. Mestrado. Curso de Pós-Graduação em Engenharia Florestal. Setor de Ciências Agrárias.

\section{MUNSELL COLOR DIVISION. Soil Color Charts. Baltimore, 1971}

PEDLEY, L. Derivation and dispersal of Acacia (Leguminosae), with particular reference to Australia, and the recognition of Senegalia and Rhacosperma. Bot. Journ. Linn. Soc., 92 : 219-254, 1986.

RAMBO, B. Leguminosae riograndenses. Pesquisas. Série Botânica, n² 23, 1966. 166 p.

RECORD, S.J. \& HESS, R.W. Timbers of the New World. New Haven, Yale University Press, 1949. $640 \mathrm{p}$.

REINDERS-GOUWENTAK, C.A. The storied structure features and the taxonomic rank of the leguminous taxa. Acta Bot. Neerl., 4: 460-470, 1955.

REINDERS-GOUWENTAK, C.A. \& RIJSDIJK, J.F. Wood anatomical characterization of the leguminous taxa. Proc. Kon. Ned. Ak. v. Wet. Ser. C., 58(1): 41-50, 1955. (resumo).

ROBBERTSE, P.J.; VENTER, G. \& RENSBURG, H.J. van. The wood anatomy of the South African Acacias. IAWA Bull., 1(3): 93-103, 1980.

ROTH, I. Estructura anatomica de la corteza de algunas especies arboreas venezolanas de Mimosacecie. Acta Botanica Venezuelica, 12 (1-4): 293-355, 1977

SENN, H.A. The relation of anatomy and cytology to the classification of the Leguminosae. Chron. Bot., 7: 306-308, 1943.

STRASSBURGER, E. Tratado de Botánica. Buenos Aires, Manuel Marin, 1949. 741 p. 
TAKHTAJAN, A.L. Flowering plants: Origin and Dispersal. Edinburgh, Oliver \& Boyd, 1969. $310 \mathrm{p}$.

TEIXEIRA, L.L. Identificação botânico-dendrológica e anatômica da madeira de seis espécies euxilóforas do sudoeste paranaense. Curitiba, Universidade Federal do Paraná, 1977. 112 p. Dissertação. Mestrado. Curso de Pós-Graduação em Engenharia Florestal. Setor de Ciências Agrárias.

TEIXEIRA, L.L.; BURGER, L.M. \& KARSTEDT, P. Estudos microscópicos do xilema e casca do gênero Dalbergia, baseados em quatro espécies do sul do Brasil. Arq. J. Bot., 22: 115-133, 1979.

TORTORELLI, L.A. Maderas y Bosques Argentinos. Buenos Aires, ACME, 1956. 910 p.

VASSAL, J. Intérêt taxonomique de la morphologie des graines dans le genre Acacia. Bull. de la Societé d'Histoire Naturel, Toulouse, 98 (3-4): 341-371, 1963.

VASSAL, J. Ontogenetic and seed research applied to the morphological, taxonomical and phylogenetic study of the genus Acacia. Travaux Lab. For. Toulouse. Tome 1, vol 8, art. 17, 1972. $125 \mathrm{p}$.

WIEDENBRUG, W. Maderas Chilenas - contribuicion a su anatomia y identificacion. Lilloa, 16: $262-375,1948$. 